\title{
Metaplastic carcinoma of the breast : Prognosis and response to systemic treatment in metastatic disease
}

\section{Takala, Sari}

2019

Takala , S , Heikkilä , P , Nevanlinna , H , Blomqvist , C \& Mattson , J 2019 , ' Metaplastic carcinoma of the breast : Prognosis and response to systemic treatment in metastatic disease ' , Breast Journal, vol. 25 , no. 3 , pp. 418-424 . https://doi.org/10.1111/tbj.13234

http://hdl.handle.net/10138/312896

https://doi.org/10.1111/tbj.13234

draft

Downloaded from Helda, University of Helsinki institutional repository.

This is an electronic reprint of the original article.

This reprint may differ from the original in pagination and typographic detail.

Please cite the original version. 


\title{
Metaplastic carcinoma of the breast: Prognosis and response to systemic treatment in metastatic disease
}

\author{
Sari Takala MD ${ }^{1}$ (D) | Päivi Heikkilä MD, $\mathrm{PhD}^{2}$ | Heli Nevanlinna $\mathrm{PhD}^{3}$ | \\ Carl Blomqvist MD, $\mathrm{PhD}^{1,4}$ | Johanna Mattson MD, $\mathrm{PhD}^{1}$
}

\author{
${ }^{1}$ Helsinki University Hospital \\ Comprehensive Cancer Centre, Helsinki, \\ Finland \\ ${ }^{2}$ Department of Pathology, University of \\ Helsinki and HUSLAB, Helsinki University \\ Hospital, Helsinki, Finland \\ ${ }^{3}$ Department of Obstetrics and \\ Gynaecology, University of Helsinki, Helsinki \\ University Hospital, Helsinki, Finland \\ ${ }^{4}$ Department of Oncology, Örebro \\ University Hospital, Örebro, Sweden \\ Correspondence \\ Sari J. Takala, Helsinki University Hospital \\ Comprehensive Cancer Centre, Helsinki, \\ Finland. \\ Email: sari.takala@hus.fi \\ Funding information \\ This work was supported by the Research \\ fund of The Hospital District of Helsinki and \\ Uusimaa.
}

\begin{abstract}
Background: Metaplastic breast carcinomas (MpBCs) are rare, aggressive breast cancers. Due to the scant literature of this disease most guidelines do not give recommendation for this entity. The aim of the study was to review the clinicopathologic features, treatment, and outcomes of the patients with $\mathrm{MpBC}$ treated at our institution.

Material and methods: We searched databases for patients with histologically confirmed MpBC from 2002 to 2016.

Results: A total of 78 patients with $\mathrm{MpBC}$ were included in the study. All histological material was reviewed by an experienced breast pathologist. Most tumors were grade 3 (83\%) and triple negative (85\%). Eighty-two percent were node negative. Sixty-four percent received adjuvant chemotherapy. The 5-year disease free survival was $63 \%$ and 5 -year breast cancer specific overall survival was $61 \%$. Tumor size and mixed metaplastic histology were associated with worse outcome in this patient group. One third of the patients $(n=28)$ had metastatic disease at initial presentation or developed metastases at follow-up. The lungs were the most common site of first distant recurrence. Half $(n=14)$ of these patients received palliative chemotherapy. Of those only $6 \%(n=2)$ had partial response and $18 \%$ had stable disease as best response to treatment. The median overall survival time with metastatic disease was only 3.4 months.

Conclusion: $\mathrm{MpBC}$ is an aggressive type of breast cancer with poor outcome despite low nodal involvement and aggressive local and systemic therapy. Tumor response to palliative systemic chemotherapy remains poor for $\mathrm{MpBC}$ patients.
\end{abstract}

\section{KEYWORDS}

chemotherapy, metaplastic breast cancer, metastatic breast cancer, prognostic factors, systemic treatment

\section{1 | INTRODUCTION}

$\mathrm{MpBC}$ is a rare but aggressive subtype of invasive mammary carcinoma accounting for less than $1 \%$ of all breast malignancies. ${ }^{1}$ It is a heterogeneous group characterized by the differentiation of the neoplastic epithelium into squamous cells and/or mesenchymal looking elements. The principal immunohistochemical characteristics of MpBC cells are that they are enriched with markers of epithelial-mesenchymal transition and cancer stem cells. ${ }^{2,3}$ The World Health Organization (WHO) classifies MpBC into low-grade adenosquamous carcinoma, fibromatosis-like metaplastic carcinoma, squamous cell carcinoma, spindle cell carcinoma, and carcinoma with 
mesenchymal differentiation (chondroid, osseous, and other types of mesenchymal differentiation). ${ }^{1} \mathrm{MpBC}$ can also present with histologic components of other conventional types of breast cancer such as invasive ductal carcinoma (IDC).

Patients with $\mathrm{MpBC}$ usually have larger, higher grade, and more often triple negative tumors compared with patients with IDC ${ }^{4-6}$ and they usually carry a worse prognoses than IDC with similar stage and grade $^{4,5,7}$ and even compared to other triple negative breast carcinomas (TNBC). ${ }^{4,6,8-10}$

According to previous studies the 5 -year overall survival (OS) rate in $\mathrm{MpBC}$ patients has been 53.7\%-71\% ${ }^{4-6,11}$ and the 5-year disease free survival (DFS) rate $45.5 \%-64 \%^{4,6,11}$ compared with 5-year OS of $81.2 \%-88 \% \%^{4,5,12}$ and 5 -year DFS of $71.2 \%^{4}$ for conventional IDC.

Although the knowledge of prognostic factors of $\mathrm{MpBC}$ is still limited, some factors have been shown to affect the outcome in MpBC. Lymph node metastasis, ${ }^{4-6,13}$ lymphovascular invasion, ${ }^{14}$ large tumor size, ${ }^{4,5,9,11}$ personal history of breast cancer, ${ }^{11}$ and positive surgical margins ${ }^{11,15}$ have previously been associated with inferior survival. In other breast cancers hormone receptor positivity improves prognosis, but in the large study $(n=2338)$ made by Wright et $\mathrm{al}^{10}$ there was no difference in 5 -year survival between hormone-positive and hormone-negative tumors in MpBC. Studies from the American SEERS database ( $n=2338$ and $n=1501$ ) have suggested that administration of radiotherapy is associated to improved survival in MpBC. ${ }^{12,16}$

Evidence for guiding management of patients with $\mathrm{MpBC}$ is limited because there are no randomized clinical trials to guide therapy selection. Currently MpBC is treated using algorithms developed for other histologic subtypes of invasive breast carcinoma. There are only small studies available regarding its response to systemic chemotherapy and they have indicated poor responsiveness of this disease to systemic agents. In a study of 21 patients receiving neoadjuvant chemotherapy the pathologic complete response rate was only $10 \% .{ }^{17}$ In another study of 11 patients in advanced disease $18.2 \%$ experienced a partial response. ${ }^{18}$

Further study is required to optimize outcomes for patients with this rare breast cancer subtype.

\section{2 | MATERIAL AND METHODS}

This study was approved by the local ethical committee. The pathology databases were searched over a 15-year period (2002-2016) for patients with a histologically confirmed diagnosis of metaplastic carcinoma who were treated at the Helsinki University Hospital Comprehensive Cancer Centre. All the cases were reviewed by a breast pathologist $(\mathrm{PH})$ to verify $\mathrm{MpBC}$ and classify them. A total of 78 patients fulfilled the criteria and were included in this study. Data regarding clinicopathologic features, treatment, recurrence, and survival were obtained. Her2 positivity was assessed by immunohistochemistry and all $2+$ or $3+$ scores were certified by fluorescent in situ hybridization. ER- and PR-positivity were defined as any nuclear labeling in $10 \%$ of tumor cells or higher. The histological grade was determined according to the Elston and Ellis modification of the Scarff-Bloom-Richardson grading system. ${ }^{19}$ Histologic subtypes were classified according to WHO classification. $\mathrm{MpBC}$ s presenting with mixed metaplastic components were classified into mixed metaplastic carcinomas and MpBCs presenting with a conventional type of breast cancer were classified into mixed type.

Loco-regional recurrence was defined as tumor recurrence in the breast, ipsilateral axilla, thoracic wall, supraclavicular fossa, or parasternal region. Distant recurrence was defined when the recurrence occurred at any other site.

Survival time, in years, was calculated from the date of operation, until the date of death, with patients who were alive censored at the date of last follow-up. DFS was calculated as the time from operation to the time of first documentation of breast cancer recurrence at any site (ie loco-regional or distant), or death due to breast cancer, whichever occurred first. Survival probabilities at 5 years were estimated using the Life Table method. Univariate and multivariate Cox regression analyses were performed to evaluate the prognostic impact of various clinicopathologic features on OS and DFS. The hazard ratios (HRs) were estimated with $95 \%$ confidence intervals (Cls).

Tumor response assessment in metastatic setting was performed by using RECIST guideline (version 1.1). ${ }^{20}$ Time to progression (TTP) was calculated from the first treatment date until the date of first progression.

Association between tumor type and clinical characteristics was tested with the Chi-square test or Fisher's exact test if applicable. Differences in survival and local recurrence by radiotherapy were tested using the log-rank test. The significance level was set at $P \leq 0.05$

\section{3 | RESULTS}

\section{1 | Clinicopathologic features and primary treatment}

78 female patients with a diagnosis of $\mathrm{MpBC}$ were identified. The clinicopathologic features and primary treatment of these patients and their tumors are summarized in Table 1 . Most patients had grade III (83\%), T2 (46\%), NO (82\%), and triple negative disease (85\%). Clinicopathologic features and primary treatment by subgroup is shown in Supplementary Table S1. The mixed type tumors were associated with more advanced T-stage $(P=0.2)$, node positivity $(P<0.0001)$ and distant metastases at diagnosis $(P=0.045)$. The most common single histologic subtype was squamous cell carcinoma (26\%). 28 patients had metastatic disease at presentation or during follow-up. The most common site of metastasis was the lungs $(n=20)$, followed by lymph nodes $(n=7)$, liver $(n=6)$, and bone $(n=6)$. Loco-regional recurrence without distant metastasis occurred in $5 \%(n=4)$ of the patients. The most common site of locoregional recurrence was the thoracic wall $(n=3)$. 
TAB LE 1 Clinicopathologic and treatment characteristics

\begin{tabular}{|c|c|}
\hline Characteristics & No. (\%) \\
\hline \multicolumn{2}{|l|}{ Age at primary diagnosis (y) } \\
\hline Median (range) & $66.6(23.9-91.7)$ \\
\hline \multicolumn{2}{|l|}{ Menopause status $(n=74)$} \\
\hline Premenopausal & $12(16)$ \\
\hline Postmenopausal & $62(84)$ \\
\hline \multicolumn{2}{|l|}{ Tumor size (mm) } \\
\hline Median (range) & $30(5.0-130.0)$ \\
\hline \multicolumn{2}{|l|}{ Tumor size $(T)(n=76)$} \\
\hline $\mathrm{T} 1$ & $22(29)$ \\
\hline T2 & $35(46)$ \\
\hline T3 & $14(18)$ \\
\hline $\mathrm{T} 4$ & $5(7)$ \\
\hline \multicolumn{2}{|l|}{ Grade } \\
\hline 1 & $3(4)$ \\
\hline 2 & $10(13)$ \\
\hline 3 & $65(83)$ \\
\hline \multicolumn{2}{|l|}{ Lymph node status $(n=71)$} \\
\hline NO & $58(82)$ \\
\hline N1 & $8(11)$ \\
\hline N2 & 2 (3) \\
\hline N3 & $3(4)$ \\
\hline \multicolumn{2}{|l|}{ Metastasis at diagnoses } \\
\hline No & $76(97)$ \\
\hline Yes & $2(3)$ \\
\hline \multicolumn{2}{|l|}{ ER status } \\
\hline Positive & $9(12)$ \\
\hline Negative & $69(88)$ \\
\hline \multicolumn{2}{|l|}{ PR status } \\
\hline Positive & 2 (3) \\
\hline Negative & $76(97)$ \\
\hline \multicolumn{2}{|l|}{ Her2 } \\
\hline Positive & $3(4)$ \\
\hline Negative & $75(96)$ \\
\hline \multicolumn{2}{|l|}{ Triple negative } \\
\hline Yes & $66(85)$ \\
\hline No & $12(15)$ \\
\hline \multicolumn{2}{|l|}{ Histologic subtype } \\
\hline Low-grade adenosquamous & $2(3)$ \\
\hline Squamous & $20(26)$ \\
\hline Spindle & $17(22)$ \\
\hline Chondroid differentiation & $11(14)$ \\
\hline Osseous differentiation & $2(3)$ \\
\hline Fibromatosis-like & $0(0)$ \\
\hline Mixed metaplastic & $9(12)$ \\
\hline Mixed type & $17(22)$ \\
\hline
\end{tabular}

(Continues)
TABLE 1 (Continued)

\begin{tabular}{|c|c|}
\hline Characteristics & No. (\%) \\
\hline \multicolumn{2}{|l|}{ Type of breast surgery } \\
\hline Mastectomy & $48(62)$ \\
\hline Breastconserving & $29(37)$ \\
\hline Biopsy & $1(1)$ \\
\hline \multicolumn{2}{|l|}{ Type of axillary surgery } \\
\hline Sentinel node biopsy & $33(42)$ \\
\hline Dissection & $38(49)$ \\
\hline None & $7(9.0)$ \\
\hline \multicolumn{2}{|l|}{ Chemotherapy (adjuvant) } \\
\hline Yes & $50(64)$ \\
\hline No & $28(36)$ \\
\hline \multicolumn{2}{|c|}{ Chemotherapy (neoadjuvant) } \\
\hline Yes & $2(3)$ \\
\hline No & $76(97)$ \\
\hline \multicolumn{2}{|l|}{ Radiotherapy } \\
\hline Yes & $47(60)$ \\
\hline No & $31(40)$ \\
\hline \multicolumn{2}{|c|}{ Radiotherapy target $(n=47)$} \\
\hline Scar & $20(43)$ \\
\hline Residual breast & $27(57)$ \\
\hline Axilla & $12(26)$ \\
\hline Clavicle fossa & $13(28)$ \\
\hline Parasternal region & $4(9)$ \\
\hline \multicolumn{2}{|l|}{ Endocrine therapy } \\
\hline Yes & $8(10)$ \\
\hline No & $70(90)$ \\
\hline \multicolumn{2}{|l|}{ Anti-Her2 therapy } \\
\hline Yes & $3(4)$ \\
\hline No & $75(96)$ \\
\hline
\end{tabular}

$E R$, oestrogen receptor; PR, progesterone receptor; HER2, human epidermal growth factor receptor 2; MpBC, metaplastic breast carcinoma.

\subsection{Survival analysis}

Five year DFS was 63\%, 5-year OS was $52 \%$, and 5 -year breast cancer specific OS was $61 \%$, with a median follow-up of 6.3 years (range $0.2-14.4$ ). Three year DFS was $63 \%$ and breast cancer specific OS $68 \%$ respectively. Univariate Cox regression analysis for associations between clinicopathologic features and OS and DFS are presented in Table 2. Tumor size and mixed subtype were associated with worse DFS and OS in univariate analyses. Age, grade, nodal status, hormone receptor, and HER2 -status did not have statistically significant association with survival outcomes. Tumor size and MpBC subtype were independent prognostic factors for OS and DFS in multivariate analysis. Kaplan-Meier analyses for associations between histologic subtypes and DFS and OS are presented in Figure 1. Radiotherapy provided an OS $(P=0.045)$ but not a loco-regional recurrence-free survival $(P=0.489)$ benefit. 


\subsection{Systemic treatment of metastatic MpBC}

Fourteen of the 28 patients with metastatic disease received palliative systemic chemotherapy and one of them received palliative endocrine therapy. The chemotherapy regimens, subtypes and response details of these 14 patients are detailed in Table 3. A total of 34 chemotherapy regimens were administered with the median number of chemotherapy lines being two. Only two patients had a partial response (PR) to first and second line chemotherapy respectively. The two responders (the latter being a patient with a BRCA2-mutation) were treated with cisplatincapecitabine (TTP 131) and FEC (TTP 270 days). The patient with a BRCA2-mutation also had stable disease (SD) receiving docetaxel as first line treatment (TTP 122 days), capecitabine as third line treatment (TTP 140 days), capecitabine-vinorelbine as fourth line treatment (TTP 143), FEC as fifth line treatment (TTP 191 days) and carboplatin-gemcitabine as sixth line treatment (TTP 121 days). In addition, one other patient had SD-response receiving FEC as second line treatment (TTP 235 days). One of the responders had squamous histologic subtype and the other one had mixed histologic type. All the other patients had either progressive (PD) or non-evaluable (NE) disease. Of the four patients with non-evaluable disease, three died shortly after the treatment and one had clinically evaluated progression. The patient receiving endocrine therapy as first line treatment had PD on letrozole (TTP 69 days). The median overall survival time with metastatic disease was 3.4 months (range, 0.07-31.2), 6.4 months (range, 0.2-31.3) for those who had $(n=15)$, and 1.1 months (range, 0.07-16.4) for those who had not $(n=13)$ received palliative chemotherapy or endocrine therapy.

In addition, we assessed the effect of palliative radiotherapy and detected only few radiological or symptomatic responses. Instead, most of the patients died shortly after the treatment due to aggressive metastatic disease (data is not shown).

\section{DISCUSSION}

We present the clinicopathologic features, treatment, and clinical outcomes of 78 patients with $\mathrm{MpBC}$ treated at our institution. In our series $82 \%$ of the patients were node-negative and $46 \%$ had T2 disease. Most of the tumors were poorly differentiated (83\%), and triple negative (85\%). Our findings are consistent with previous studies which suggested that the majority of $\mathrm{MpBC}$ tumors are triple negative (48\%-86\%) and node-negative (51\%-79\%). ${ }^{4,6,11,13,15}$ Also, in previous studies most of the patients have had Grade III, T2 disease, with the rates of $77 \%-86 \%$ and $52 \%-62 \%$. 5,11

Our study confirms the poor prognosis of this disease with 5 years OS of only $52 \%$, which is to be compared with the 5 years overall breast cancer survival of $86 \%$-88\% between 2000 and 2014 in the Nordic Cancer Registry. ${ }^{21}$ The findings are similar to those reported by Song et al ${ }^{4}$ with a 5 -year OS of $54.5 \%$ and DFS of $45.5 \%$ ( $n=55$ ) and Cimino-Matthews et al ${ }^{11}$ with a 5 -year OS of $69 \%$, recurrence-free survival (RFS) of $64 \%$ and distant metastasis-free survival (DMFS) of $75 \%(n=45)$. The pattern of recurrence seems to be different from other types of breast cancer with the lungs being the most common site of first distant metastasis while bone usually is the most common site in general breast cancer materials. ${ }^{22}$

In the present study, only tumor size and mixed metaplastic histology were associated with inferior outcome. Also, in other studies tumor size has been a significant prognostic factor. ${ }^{4,5,9,11}$ Histologic subtype has also previously been reported to be associated with outcome ${ }^{12}$; as in the present study the group of spindle and mixed spindle and squamous subtypes had inferior breast cancer specific

TAB LE 2 Univariate and multivariate Cox regression analyses for association of clinicopathologic features with clinical outcome

\begin{tabular}{|c|c|c|c|c|c|c|c|c|}
\hline Characteristics & \multicolumn{4}{|l|}{ Overall survival } & \multicolumn{4}{|c|}{ Disease free survival } \\
\hline Age (continuous) & $1.02(0.99-1.05)$ & 0.142 & & & $1.02(0.99-1.05)$ & 0.197 & & \\
\hline Tumor size $(\mathrm{cm})$ & $1.24(1.10-1.39)$ & 0.000 & $1.23(1.09-1.34)$ & 0.001 & $1.22(1.08-1.38)$ & 0.001 & $1.21(1.08-1.37)$ & 0.001 \\
\hline $\begin{array}{l}\text { Nr of metastatic } \\
\text { lymph nodes }\end{array}$ & $1.00(0.93-1.07)$ & 0.895 & & & $1.04(0.99-1.08)$ & 0.133 & & \\
\hline $\begin{array}{l}\text { ER-status } \\
\text { Positive vs negative }\end{array}$ & $0.84(0.26-2.80)$ & 0.782 & & & $0.82(0.25-2.71)$ & 0.741 & & \\
\hline $\begin{array}{l}\text { PR-status } \\
\text { Positive vs negative }\end{array}$ & $0.05(0.00-220.5)$ & 0.477 & & & $0.05(0.00-331)$ & 0.499 & & \\
\hline
\end{tabular}

$\mathrm{Cl}$, confidence interval; ER, oestrogen receptor; HER2, human epidermal growth factor receptor 2; HR, hazard ratio; PR, progesterone receptor. 


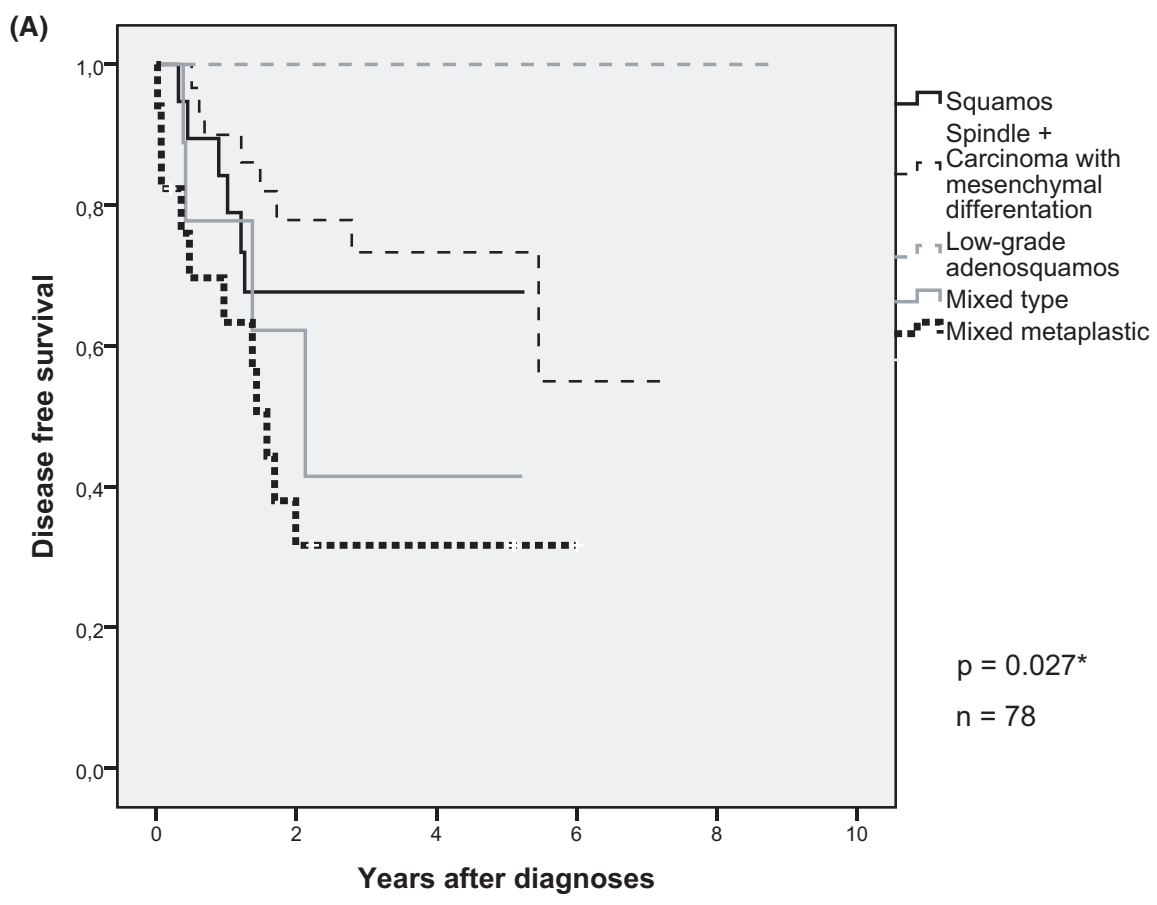

FIGURE 1 A, Disease-free survival by histologic subtype $\left(P=0.027^{*}\right)$. B, Overall survival by histologic subtype $\left(P=0.059^{*}\right)$ ${ }^{*} P$ values were obtained from log rank test
(B)

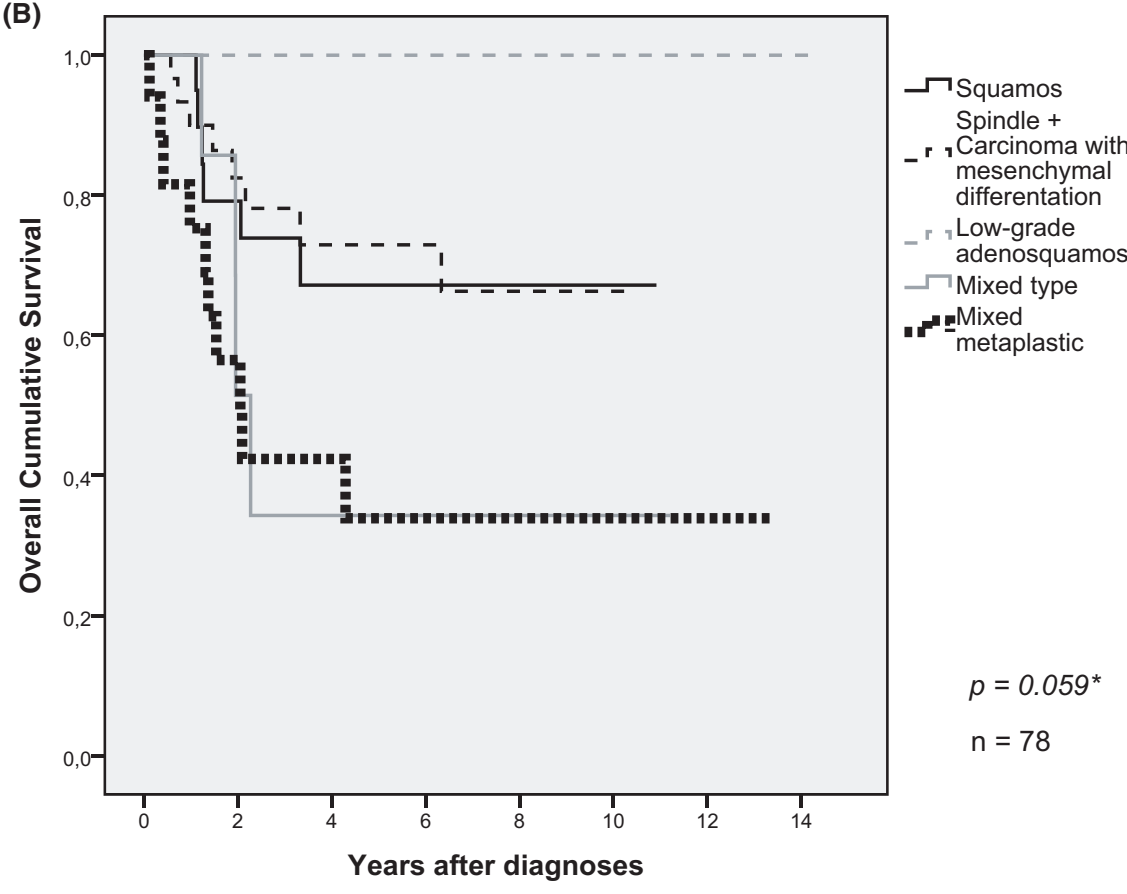

outcome compared to a group of matrix producing and squamous subtypes. Also, Cimino-Matthews et al ${ }^{9}$ reported that mixed histologic subtype was associated with worse outcome. Our findings also suggested radiotherapy to be associated with improved survival, however, this might be due to selection bias.

Only $5 \%$ of our patients experienced loco-regional recurrence. Compared with previous studies the loco-regional recurrence rate in our series was low. In the study by Edenfield et al ${ }^{15} 40 \%$ developed metastatic disease and $12 \%$ loco-regional recurrence despite most patients having $\mathrm{T} 1$ disease (40\%) and $60 \%$ receiving radiotherapy $(n=25)$. The recurrence rates were similar in a study by Song et $\mathrm{al}^{4}(\mathrm{n}=55)$ with 23 patients $(42 \%)$ developing metastatic disease and 10 patients (18\%) loco-regional recurrence. In the latter series the higher recurrence rate may at least partly have been due to the more advanced stage as well as less aggressive local treatment, as the median tumor size was larger than in our study $(5 \mathrm{~cm}$ vs $3 \mathrm{~cm})$, fewer had node-negative disease (64\% vs $82 \%$ ) and fewer patients received radiotherapy (49\% vs $60 \%$ ). 


\begin{tabular}{|c|c|c|c|}
\hline Line & CT Regimen & Subtype & Response \\
\hline 1 & $\begin{array}{l}\text { Capecitabine (2) } \\
\text { Cisplatin-capecitabine (1) } \\
\text { Docetaxel/paclitaxel (6) } \\
\text { Cisplatin-vinorelbine (1) } \\
\text { Docetaxel-gemsitabine (1) } \\
\text { VMF (1) } \\
\text { FEC (1) } \\
\text { Docetaxel-cisplatin (1) }\end{array}$ & $\begin{array}{l}\text { MM, CWMD } \\
\text { SC } \\
\text { SpC(2), MT(4) } \\
\text { MM } \\
\text { SpC } \\
\text { SC } \\
\text { MM } \\
\text { MT }\end{array}$ & $\begin{array}{l}\text { PD (1), NE (1) } \\
\text { PR (1) } \\
\text { SD (1), PD (2), NE (3) } \\
\text { PD (1) } \\
\text { PD (1) } \\
\text { PD (1) } \\
\text { PD (1) } \\
\text { PD (1) }\end{array}$ \\
\hline 2 & $\begin{array}{l}\text { Docetaxel/paclitaxel (1) } \\
\text { Paclitaxel-carboplatin (2) } \\
\text { FEC (5) } \\
\text { Carboplatin-gemcitabine (1) }\end{array}$ & $\begin{array}{l}\text { MM } \\
\text { SC, SpC } \\
\text { SpC, MM, SC, MT(2) } \\
\text { MT }\end{array}$ & $\begin{array}{l}\text { PD (1) } \\
\text { PD (2) } \\
\operatorname{PD~(3),~SD~(1),~PR~(1)~} \\
\text { PD (1) }\end{array}$ \\
\hline 3 & $\begin{array}{l}\text { Paclitaxel-carboplatin (1) } \\
\text { Docetaxel (1) } \\
\text { Gemcitabine-cisplatin (1) } \\
\text { Capesitabine (1) } \\
\text { Doxorubicin-Cyclophosphamide (1) }\end{array}$ & $\begin{array}{l}\text { MM } \\
\text { MM } \\
\text { SC } \\
\text { MT } \\
\text { SpC }\end{array}$ & $\begin{array}{l}\text { PD (1) } \\
\text { PD (1) } \\
\text { PD (1) } \\
\text { SD (1) } \\
\text { PD (1) }\end{array}$ \\
\hline 4 & $\begin{array}{l}\text { Docetaxel (1) } \\
\text { Capecitabine-vinorelbine (2) }\end{array}$ & $\begin{array}{l}\text { SC } \\
\text { MT, SpC }\end{array}$ & $\begin{array}{l}\mathrm{PD}(1) \\
\mathrm{SD}(1), \mathrm{PD}(1)\end{array}$ \\
\hline 5 & $\operatorname{FEC~(1)~}$ & MT & $\mathrm{SD}(1)$ \\
\hline 6 & Carboplatin-gemcitabine (1) & MT & $\mathrm{SD}(1)$ \\
\hline 7 & Weekly doxorubicin (1) & MT & PD (1) \\
\hline
\end{tabular}

TABLE 3 Chemotherapy regimens and tumor response in metastatic setting

CWMD, carcinoma with mesenchymal differentiation; FEC, fluorouracil-epirubicin-cyclophosphamide; MM, mixed metaplastic; MT, mixed type; NE, nonevaluable; PD, progressive disease; PR, partial response; SC, squamous cell; SD, stable disease; SpC, spindle cell; VMF, vincristine-methotrexate-5-fluorouracil.

We found the response to palliative systemic therapy in metastatic MpBC poor. PR as best response was seen only in $6 \%$ of the cases and SD in $18 \%$ of the cases. The few responses were seen in the patients treated with anthracyclines ie FEC-regimen and capecitabine-containing regimes. Also, in some previous studies capecitabine has provided survival benefit in patients with TNBC. ${ }^{23}$

Palliative systemic treatment for patients with metastatic disease has been ineffective also in previous studies, although the number of published cases still remains low. In one study of 12 patients with metastatic $\mathrm{MpBC}$ who received palliative chemotherapy, only 2 patients (16.7\%) had PR and all the other 10 patients (83.3\%) experienced PD. One of the responders received oral uracil-Tegafur and the other was treated with weekly paclitaxel and 24-h high-dose infusional fluorouracil and Leucovorin. ${ }^{18}$ In another study of 23 patients who received palliative chemotherapy, mainly consisting of anthracyclins, carboplatin, taxanes, capecitabine, and vinorelbine, only 5 patients $(21.7 \%)$ had PR and another 5 patients $(21.7 \%$ ) had SD. ${ }^{4}$ Finally in a study of 25 patients with metastatic MpBC, the objective response rate (ORR) was $38.9 \%$, which is in contrast with the other results. Subgroup analysis did not show significant differences in ORR between the chemotherapy regimens and the chemoresponsiveness of $\mathrm{MpBC}$ was similar to triple negative IDC. ${ }^{6}$

In conclusion, $\mathrm{MpBC}$ is an extremely aggressive type of breast cancer with poor outcome despite of low nodal involvement and aggressive local and systemic therapy. We could verify that mixed histologic subtypes and large tumor size were poor prognostic markers.
Given the poor prognoses and reduced response to treatment for $\mathrm{MpBC}$, new treatment paradigms need to be identified.

\section{CONFLICT OF INTEREST}

The authors report no conflicts of interest.

\section{ORCID}

Sari Takala iD https://orcid.org/0000-0001-7305-9706

\section{REFERENCES}

1. Lakhani S, Ellis I, Schnitt S, eds. WHO classification of tumours of the breast. Lyon, France: IARC; 2012.

2. Cooper CL, Karim RZ, Selinger C, Carmalt H, Lee CS, O'Toole SA. Molecular alterations in metaplastic breast carcinoma. J Clin Pathol. 2013;66:522-528.

3. Hennessy Bt, Gonzalez-Angulo A-m, Stemke-Hale K, et al. Characterization of a naturally occurring breast cancer subset enriched in epithelial-to-mesenchymal transition and stem cell characteristics. Cancer Res. 2009;69:4116-4124.

4. Song Y, Liu X, Zhang G, et al. Unique clinicopathological features of metaplastic breast carcinoma compared with invasive ductal carcinoma and poor prognostic indicators. World J Surg Oncol. 2013;11:129-7819-11-129.

5. Nelson RA, Guye ML, Luu T, Lai LL. Survival outcomes of metaplastic breast cancer patients: results from a US population-based analysis. Ann Surg Oncol. 2015;22:24-31. 
6. Lee H, Jung S-Y, Ro JY, et al. Metaplastic breast cancer: clinicopathological features and its prognosis. J Clin Pathol. 2012;65:441-446.

7. Lai H-W, Tseng L-M, Chang T-W, et al. The prognostic significance of metaplastic carcinoma of the breast (MCB)-a case controlled comparison study with infiltrating ductal carcinoma. Breast. 2013;22:968-973.

8. Aydiner A, Sen F, Tambas M, et al. Metaplastic breast carcinoma versus triple-negative breast cancer: survival and response to treatment. Medicine (Baltimore). 2015;94:e2341.

9. Jung S-Y, Kim HY, Nam B-H, et al. Worse prognosis of metaplastic breast cancer patients than other patients with triple-negative breast cancer. Breast Cancer Res Treat. 2010;120:627-637.

10. Lester TR, Hunt KK, Nayeemuddin KM, et al. Metaplastic sarcomatoid carcinoma of the breast appears more aggressive than other triple receptor-negative breast cancers. Breast Cancer Res Treat. 2012;131:41-48.

11. Cimino-Mathews A, Verma S, Figueroa-Magalhaes MC, et al. A clinicopathologic analysis of 45 patients with metaplastic breast carcinoma. Am J Clin Pathol. 2016;145:365-372.

12. Paul Wright G, Davis AT, Koehler TJ, Melnik MK, Chung MH. Hormone receptor status does not affect prognosis in metaplastic breast cancer: a population-based analysis with comparison to infiltrating ductal and lobular carcinomas. Ann Surg Oncol. 2014;21:3497-3503.

13. Zhang Y, Lv F, Yang Y, et al. Clinicopathological features and prognosis of metaplastic breast carcinoma: experience of a major chinese cancer center. PLoS One. 2015;10:e0131409.

14. Rakha Ea, Tan Ph, Varga Z, et al. Prognostic factors in metaplastic carcinoma of the breast: a multi-institutional study. Br J Cancer. 2015;112:283-289.

15. Edenfield J, Schammel C, Collins J, et al. Metaplastic breast cancer: molecular typing and identification of potential targeted therapies at a single institution. Clin Breast Cancer. 2016.

16. Tseng WH, Martinez SR. Metaplastic breast cancer: to radiate or not to radiate? Ann Surg Oncol. 2011;18:94-103.

17. Hennessy BT, Giordano S, Broglio K, et al. Biphasic metaplastic sarcomatoid carcinoma of the breast. Ann Oncol. 2006;17:605-613.

18. Chen IC, Lin CH, Huang CS, et al. Lack of efficacy to systemic chemotherapy for treatment of metaplastic carcinoma of the breast in the modern era. Breast Cancer Res Treat. 2011;130: 345-351.

19. Elston CW, Ellis IO. Pathological prognostic factors in breast cancer. I. The value of histological grade in breast cancer: experience from a large study with long-term follow-up. Histopathology. 1991;19:403-410.

20. Eisenhauer EA, Therasse P, Bogaerts J, et al. New response evaluation criteria in solid tumours: revised RECIST guideline (version 1.1). Eur J Cancer. 2009;45(2):228-247.

21. Engholm G, Ferlay J, Christensen N. NORDCAN: Cancer Incidence, Mortality, Prevalence and Survival in the Nordic Countries, Version 7.3 (08.07.2016). Association of the Nordic Cancer Registries. Danish Cancer Society. http://www.ancr.nu. Accessed June 15, 2017.

22. Kamby G, Vejborg I, Kristensen B, Olsen LO, Mouridsen HT. Metastatic pattern in recurrent breast cancer: Special reference to intrathoracic recurrences. Cancer. 1988;62:2226-2233.

23. Joensuu H, Kellokumpu-Lehtinen PL, Huovinen R, et al. Adjuvant capecitabine in combination with docetaxel, epirubicin, and cyclophosphamide for early breast cancer: the randomized clinical FinXX trial. JAMA Oncol. 2017;3:793-800.

\section{SUPPORTING INFORMATION}

Additional supporting information may be found online in the Supporting Information section at the end of the article.

How to cite this article: Takala S, Heikkilä P, Nevanlinna H, Blomqvist C, Mattson J. Metaplastic carcinoma of the breast: Prognosis and response to systemic treatment in metastatic disease. Breast J. 2019;00:1-7. https://doi.org/10.1111/ tbj.13234 